\title{
Efeitos gênicos do teor de cálcio em grãos de feijão
}

\author{
Genetic effects of the calcium content in common bean
}

\author{
Evandro Jost ${ }^{\mathrm{I}}$ Nerinéia Dalfollo Ribeiro ${ }^{\mathrm{II}}$ Sandra Maria Maziero ${ }^{\mathrm{III}}$ \\ Taiguer Cerutti ${ }^{\text {III }}$ Daniele Piano Rosa ${ }^{\mathrm{II}}$
}

\section{RESUMO}

O objetivo deste trabalho foi investigar a existência de efeito materno para o teor de cálcio em grãos de feijão e obter estimativas de herdabilidade e de efeitos gênicos para seleção em gerações precoces. Os cruzamentos controlados foram realizados entre as cultivares "Pérola" $x$ "TPS Bonito" $e$ "TPS Bonito" x "BRS Expedito". As gerações $F_{1}, F_{1}$ recíproco, $F_{2}, F_{2}$ recíproco, $F_{3}, F_{3}$ recíproco, $R C P_{1}$ e $R C P_{2}$ foram obtidas para cada combinação híbrida. O teor de cálcio foi determinado por meio de digestão nítrico-perclórica e leitura em espectrofotômetro de absorção atômica. Variabilidade genética para o teor de cálcio nos grãos foi constatada nos diferentes cruzamentos, com maior influência dos efeitos gênicos aditivos, além de expressão de efeito materno. Estimativas de herdabilidade, em sentido amplo, de 66,75\% e de 74,65\% e, em sentido restrito, de 47,00\% e 63,61\%, foram obtidas para os cruzamentos "Pérola” $x$ "TPS Bonito" $e$ "TPS Bonito" $x$ "BRS Expedito", respectivamente. A seleção realizada em gerações precoces poderá ser efetiva no desenvolvimento de germoplasma de feijão com alto teor de cálcio nos grãos.

Palavras-chave: Phaseolus vulgaris L., variabilidade genética, gerações precoces, efeito materno, herdabilidade, ganhos por seleção.

\section{ABSTRACT}

The objective of this research was to investigate the existence of maternal effect in calcium content of common bean grains and to estimate heritability and gene effect by selection in early generations. The controlled crossings were performed among the cultivars 'Pérola' $x$ 'TPS Bonito' and 'TPS Bonito' $x$ 'BRS Expedito'. The $F_{1}, F_{1}$ reciprocal, $F_{2}, F_{2}$ reciprocal, $F_{3}, F_{3}$ reciprocal, backcross 1 and backcross 2 generations were obtained for each hybrid combination. The calcium content was ascertained by nitric-perchloric digestion and determination on the atomic absorption spectrophotometer. Genetic variability in grain calcium content was revealed in two crosses with higher influence of the additive genetic effect, beyond expression of maternal effect. Estimates of heritability in the broad sense were of $66.75 \%$ and $74.65 \%$ and in the narrow sense of $47.00 \%$ and $63.61 \%$, in the crosses 'Pérola' $x$ 'TPS Bonito' and 'TPS Bonito' $x$ 'BRS Expedito', respectively. The selection performed in the early generation may be effective for development of common bean germplasm with higher calcium content.

Key words: Phaseolus vulgaris L., genetic variability, early generation, maternal effect, heritability, genetic gains.

\section{INTRODUÇÃO}

A deficiência de cálcio no organismo provoca anormalidades na estrutura óssea, causando osteoporose, osteomalacia e raquitismo (CZAJKANARINS, 1998). Isso porque a principal função do cálcio é a formação dos ossos e dos dentes. Além disso, ele exerce papel vital no crescimento, na contração e no relaxamento muscular e também é um co-fator/ regulador de várias reações bioquímicas (FRANCO, 1999).Para suprir as necessidades diárias de um indivíduo adulto, recomenda-se a ingestão de $1,2 \mathrm{~g} \mathrm{dia}^{-1}$

'Programa de Pós-graduação em Agronomia (PPGA), Universidade Federal de Santa Maria (UFSM), 97105-900, Santa Maria, RS, Brasil.

IIDepartamento de Fitotecnia, Centro de Ciências Rurais (CCR), UFSM, 97105-900, Santa Maria, RS, Brasil. E-mail: neiadr@smail.ufsm.br. Autor para correspondência.

IIICurso de Agronomia, CCR, UFSM, Santa Maria, RS, Brasil. 
de cálcio (NATIONAL RESEARCH COUNCIL, 1989). O leite e os seus derivados são fontes biodisponíveis de cálcio, entretanto, são produtos inacessíveis à parcela da população brasileira de menor poder aquisitivo. Além disso, algumas pessoas apresentam intolerância à lactose, por isso, fontes alternativas de alimentos devem ser avaliadas para a suplementação de cálcio na dieta.

O feijão (Phaseolus vulgaris L.) foi a terceira melhor opção como fonte de cálcio em um estudo realizado com 39 espécies de origem vegetal (STEVENS, 1974). Quando comparado a outras leguminosas, o feijão tem $50 \%$ a mais de cálcio que o grão-de-bico e $100 \%$ a mais que a lentilha (SEBASTIÁ et al., 2001). Além disso, o cálcio presente nas vagens e nos grãos imaturos do feijão vagem é prontamente absorvido pelo ser humano (GRUSAK et al., 1996).

O teor de cálcio nos grãos de feijão varia conforme a cultivar. No Brasil, valores entre 0,30 e 2,80g de $\mathrm{Ca} \mathrm{kg}^{-1}$ de matéria seca (MS) foram observados em 21 linhagens de feijão (MESQUITA et al., 2007). Variabilidade genética de 0,24 a $0,72 \mathrm{~g} \mathrm{de} \mathrm{Ca} \mathrm{kg}^{-1} \mathrm{de} \mathrm{MS}$ foi verificada em Burundi (BARAMPAMA \& SIMARD, 1993) e de 1,7 a 4,0g de $\mathrm{Ca} \mathrm{kg}^{-1}$ de MS no México (GUZMÁN-MALDONADO et al., 2000). Como há variabilidade genética para o teor de cálcio em grãos de feijão, é possível selecionar genótipos com maior teor deste mineral. Para tanto, se faz necessário o conhecimento dos efeitos gênicos do teor de cálcio em feijão para que o programa de melhoramento obtenha maior eficiência na identificação de germoplasma, que poderá ser utilizado na alimentação para prevenir ou minimizar os problemas decorrentes da deficiência de cálcio no organismo.

A herdabilidade, em sentido amplo, do teor de cálcio foi determinada em vagens e em grãos imaturos de feijão e valores entre 48 e $50 \%$ foram obtidos (QUINTANA et al., 1999). Contudo, os efeitos gênicos do teor de cálcio em grãos maduros de feijão não são conhecidos e há dúvidas também se essa característica é dependente do tegumento ou dos cotilédones. No entanto, há evidências de que $67 \%$ a $81 \%$ do cálcio estão contidos no tegumento dos grãos de feijão (MORAGHAN et al., 2006). Portanto, se ocorre efeito materno na expressão do teor de cálcio em feijão, a semente $\mathrm{F}_{1}$, obtida no cruzamento, apresentará tegumento e cotilédones em gerações diferentes, pois o tegumento é tecido materno e os cotilédones são produtos da fecundação (RAMALHO et al., 2000). Isso tem implicação direta na condução das populações segregantes em programas de melhoramento, pois o fenótipo do descendente será dependente do genótipo materno, conforme já constatado para o teor de proteína
(LELEJI et al., 1972) e para o tempo de cozimento em grãos de feijão (RIBEIRO et al., 2006).

O objetivo deste trabalho foi investigar a existência de efeito materno na expressão do teor de cálcio, bem como estimar a herdabilidade, os efeitos gênicos e os ganhos por seleção para o teor de cálcio nos grãos de feijão em gerações segregantes oriundas das combinações "Pérola" $x$ "TPS Bonito" e "TPS Bonito" x "BRS Expedito".

\section{MATERIAL E MÉTODOS}

Os blocos de cruzamentos foram conduzidos em casa-de-vegetação do Departamento de Fitotecnia, da Universidade Federal de Santa Maria (UFSM), Santa Maria, RS. A identificação dos genitores contrastantes para o teor de cálcio nos grãos foi realizada com base em avaliação prévia da composição de minerais em grãos de acessos de feijão do Banco de Germoplasma da UFSM. Os cruzamentos controlados foram realizados entre as cultivares: (a) 1 . "Pérola" $\left(1,37 \mathrm{~g} \mathrm{~kg}^{-1}\right.$, elevado teor de cálcio) x 2. "TPS Bonito" $\left(0,84 \mathrm{~g} \mathrm{~kg}^{-1}\right.$, reduzido teor de cálcio); (b) 1. "TPS Bonito" $\left(0,84 \mathrm{~g} \mathrm{~kg}^{-1}\right.$, reduzido teor de cálcio) x 2. "BRS Expedito" $\left(1,32 \mathrm{~g} \mathrm{~kg}^{-1}\right.$, elevado teor de cálcio).

No período de outono-inverno de 2006, foram obtidas as sementes $\mathrm{F}$ ( 19 x 20 ) e F1 recíproco (29x $\left.1 \delta^{\star}\right)$ para as combinações "Pérola" $\mathrm{x}$ "TPS Bonito" e "TPS Bonito" x "BRS Expedito". Parte destas sementes foram semeadas na primavera-verão de 2006 , sendo que foram obtidas as sementes $\mathrm{F}_{2}$ (autofecundação das plantas $\mathrm{F}_{1}$ ), $\mathrm{F}_{2}$ recíproco (autofecundação das plantas $\mathrm{F}_{1}$ recíproco), retrocruzamento $1\left(\mathrm{RCP}_{1}: \mathrm{F}_{1} \times 1\right)$ e retrocruzamento 2 $\left(\mathrm{RCP}_{2}: \mathrm{F}_{1} \times 2\right)$. Sementes $\mathrm{F}_{1}$ e $\mathrm{F}_{1}$ recíproco foram obtidas simultaneamente para possibilitar a avaliação de sementes desenvolvidas sob as mesmas condições de ambiente e com a mesma idade. No outono-inverno de 2007, foram obtidas as gerações $F_{3}$ (autofecundação das plantas $\mathrm{F}_{2}$ ) e $\mathrm{F}_{3}$ recíproco (autofecundação das plantas $\mathrm{F}_{2}$ recíproco) e retrocruzamentos de segunda geração (autofecundação das plantas retrocruzadas) para serem utilizadas na obtenção das estimativas de herdabilidade e de ganhos por seleção, caso fosse constatado efeito materno. Os cruzamentos foram realizados com emasculação do botão floral, empregando-se o método de entrelaçamento (PETERNELLI\& BORÉM, 1999).

A semeadura foi realizada em vasos plásticos com capacidade para 5 litros, sendo cultivadas duas plantas em cada vaso. Uma mistura de solo + casca de arroz carbonizada + substrato comercial Plantimax ${ }^{\circledR}$ foi empregada na proporção volumétrica de 2:1:1. O solo 
utilizado foi o Argissolo Bruno-Acinzentado alítico típico, com a seguinte composição química: $\mathrm{pH}\left(\mathrm{H}_{2} 0\right)$ : 5,5; matéria orgânica: $2,2 \%$; fósforo: $6,8 \mathrm{mg} \mathrm{dm}^{-3}$; potássio: $68 \mathrm{mg} \mathrm{dm}^{-3}$; cálcio: $5,5 \mathrm{cmol} \mathrm{dm}^{-3}$; magnésio: $2,7 \mathrm{cmol}_{\mathrm{c}} \mathrm{dm}^{-3}$. A correção da fertilidade do solo e a aplicação de nitrogênio em cobertura foram efetuadas com base na análise química do solo. Irrigações diárias foram realizadas para suprir a demanda hídrica das plantas e o controle de pragas e de moléstias foi realizado com a aplicação de produtos químicos, sempre que necessário, a fim de garantir a sanidade das plantas e a integridade dos botões florais.

$\mathrm{Na}$ maturação realizou-se a colheita e os grãos obtidos foram secados em estufa $\left(65 \mathrm{a} 70^{\circ} \mathrm{C}\right)$ até umidade média de $13 \%$. Amostras de $5 \mathrm{~g}$ de grãos das gerações precoces foram moídas em micromoinho até obtenção de partículas inferiores a $1 \mathrm{~mm}$. As análises para a determinação do teor de cálcio foram realizadas no Laboratório de Ecologia Florestal (LABEFLO), na UFSM. O teor de cálcio foi determinado no extrato da digestão nítrico-perclórica, de acordo com a metodologia descrita em MIYAZAWA et al. (1999). As quantificações dos teores de cálcio foram obtidas por visualização de registros, por meio de espectrofotômetro de absorção atômica, utilizando comprimento de onda de 422,70nm.

Os dados obtidos em cada combinação híbrida, para os genitores e as gerações $F_{1}$ e $F_{2}$ e seus respectivos recíprocos, foram submetidos à análise da variância e teste $\mathrm{F}$ a $5 \%$ de probabilidade, considerando o efeito de gerações como aleatório. $\mathrm{O}$ delineamento adotado foi o inteiramente casualizado, considerando seis repetições para os genitores, quatro para as gerações $\mathrm{F}_{1}$ e $\mathrm{F}_{1}$ recíproco e 12 para as gerações $\mathrm{F}_{2}$ e $\mathrm{F}_{2}$ recíproco. Para testar a hipótese de efeito materno, efetuou-se a comparação entre as médias pelo teste $t$ a $5 \%$ de significância para os contrastes $\mathrm{P}_{1} v s \mathrm{P}_{2}, \mathrm{P}_{1} v s \mathrm{~F}_{1}$ $\mathrm{P}_{2}$ vs $\mathrm{F}_{1}$ recíproco, $\mathrm{F}_{1}$ vs $\mathrm{F}_{1}$ recíproco e $\mathrm{F}_{2}$ vs $\mathrm{F}_{2}$ recíproco:

As estimativas dos parâmetros genéticos foram obtidas com as variâncias dos genitores $\mathrm{P}_{1}$ e $\mathrm{P}_{2} \mathrm{e}$ das gerações $\mathrm{F}_{1}, \mathrm{~F}_{2}, \mathrm{RCP}_{1}$ e RCP $\mathrm{R}_{2}$, com base na geração dos cotilédones. Para cada combinação híbrida, foram utilizadas seis repetições para os genitores, 12 para a geração $F_{1}, 24$ para as gerações $F_{2}$ e 12 para as gerações $\mathrm{RCP}_{1}$ e RCP ${ }_{2}$.

$\mathrm{A}^{2}$ herdabilidade foi estimada em sentido

amplo $h_{a}^{2}=\frac{\sigma_{g}^{2}}{\sigma_{P}^{2}}$ e, em sentido restrito $h_{a}^{2}=\frac{\sigma_{A}^{2}}{\sigma_{P}^{2}}$, de acordo com o método dos retrocruzamentos proposto por WARNER (1952). Sendo que: variância aditiva: $\sigma_{\mathrm{A}}^{2}=$ $2 \sigma_{\mathrm{F}_{2}}^{2}-\left(\sigma_{\mathrm{RCP}_{1}}^{2}+\sigma_{\mathrm{RCP}_{2}}^{2}\right)$ variância fenotípica: $\sigma_{\mathrm{P}}^{2}=\sigma_{\mathrm{F}_{2}}^{2} \mathrm{e}$ variância de ambiente èm $\mathrm{F}_{2}: \sigma_{\mathrm{E}}^{2}=1 / 3\left(\sigma_{\mathrm{F}_{1}}^{2}+\sigma_{\mathrm{P}_{1}}^{2}+\sigma_{\mathrm{P}_{2}}^{2}\right)$.
A heterose na geração $F_{1}$ foi quantificada pela forma percentual, tanto para a relacionada com a média dos genitores ( $\left.H \%=\frac{F_{1}-P}{P} \times 100\right)$ quanto para a heterobeltiose $\left(H T \%=\frac{F_{1}-M P}{M P} \times 100\right)$, considerando-se $P=\frac{P_{1}+P_{2}}{2}$ e $M P=$ melhor pai. Para a predição de ganhos pơr seleção, foi considerada a seleção de $25 \%$ das plantas $\mathrm{F}_{2}$ (grãos com tegumento em geração $F_{3}$ e cotilédones em geração $F_{2}$ ) com maior teor de cálcio. $\mathrm{O}$ ganho esperado, considerando-se a seleção e a recombinação dos indivíduos superiores em plantas $\mathrm{F}_{2}$ (grãos com cotilédones em geração $\mathrm{F}_{2}$ ), foi estimado pela expressão: $\Delta G=D S x h{ }_{r}^{2} \mathrm{e}$, $\Delta G(\%)=\frac{\Delta G \times 100}{\bar{F}_{2}}$ em que $D S$ é o diferencial de seleção, expresso por $\bar{X}_{s}-\bar{X}_{0}$, sendo $\bar{X}_{s}=$ média dos grãos com cotilédones em plantas selecionadas na geração $\mathrm{F}_{2}$ e $\bar{X}_{0}=$ média dos grãos com cotilédones em plantas da geração $\mathrm{F}_{2}$. As análises genéticoestatísticas foram implementadas com o auxílio do programa GENES (CRUZ, 2006).

\section{RESULTADOS E DISCUSSÃO}

Neste estudo, foi constatado efeito significativo para o teor de cálcio nos grãos de feijão a partir dos cruzamentos realizados (Tabela 1), denotando a presença de variabilidade genética para o teor de cálcio nos genitores e nas gerações $\mathrm{F}_{1}, \mathrm{~F}_{1}$ recíproco, $\mathrm{F}_{2}$ e $\mathrm{F}_{2}$ recíproco, em cada combinação híbrida. Entretanto, maior probabilidade de sucesso na seleção é esperada no cruzamento "Pérola" $\mathrm{x}$ "TPS Bonito", pois estimativa de $I_{V}=\frac{C V_{G}}{C V_{E}}$ próxima à unidade foi obtida, indicando maior expressão da variabilidade genética.

No cruzamento "Pérola" $\left(0,86 \mathrm{~g} \mathrm{~kg}^{-1}\right.$ de MS $)$ x "TPS Bonito" $\left(0,58 \mathrm{~g} \mathrm{~kg}^{-1}\right.$ de MS $)$, o contraste $\mathrm{P}_{1}$ vs $\mathrm{P}_{2}$ foi significativo, expressando que houve diferenças genéticas entre os genitores (Figura 1). Os contrastes $\mathrm{P}_{1}$ vs $\mathrm{F}_{1}$ e $\mathrm{P}_{2}$ vs $\mathrm{F}_{1}$ recíproco não foram significativos e as médias das gerações $F_{1}$ e $F_{1}$ recíproco foram similares aos genitores maternos utilizados nos cruzamentos controlados. Dessa maneira, as sementes $\mathrm{F}_{1}$ obtidas não representaram o produto da fecundação entre os genitores, revelando que o teor de cálcio nos grãos de feijão depende do tegumento, que é tecido materno. Assim, as sementes $\mathrm{F}_{1}$ apresentaram tegumento e cotilédones em gerações diferentes, devido ao fato de que o teor de cálcio se concentra, principalmente, no tegumento das sementes de feijão (MORAGHAN et al., 2006). 
Tabela 1 - Estimativas dos quadratórios médios para o teor de cálcio em grãos de feijão, considerando os genitores $\left(P_{1}\right.$ e $\left.P_{2}\right)$ e as gerações $F_{1}$, $\mathrm{F}_{1}$ recíproco, $\mathrm{F}_{2}$ e $\mathrm{F}_{2}$ recíproco obtidas nas combinações híbridas "Pérola" x "TPS Bonito" e "TPS Bonito" $\mathrm{x}$ "BRS Expedito". Santa Maria - RS, UFSM, 2007.

\begin{tabular}{|c|c|c|c|}
\hline \multirow{2}{*}{ Causas da variação } & \multirow{2}{*}{ GL } & & \\
\hline & & "Pérola" x "TPS Bonito" & "TPS Bonito" x "BRS Expedito" \\
\hline Tratamento & 5 & $0,248939^{*}$ & $0,184869^{*}$ \\
\hline Resíduo & 38 & 0,026763 & 0,036418 \\
\hline Total & 43 & - & - \\
\hline Média & & 0,83 & 0,83 \\
\hline CVE $(\%)$ & & 19,81 & 23,02 \\
\hline CVG $(\%)$ & & 21,54 & 17,55 \\
\hline $\mathrm{CVG} / \mathrm{CVE}$ & & 1,09 & 0,76 \\
\hline
\end{tabular}

* Significativo pelo teste $\mathrm{F}$ a $5 \%$ de probabilidade.

As gerações $F_{1}$ e $F_{1}$ recíproco diferiram significativamente, comprovando que o fenótipo do descendente será dependente do genitor materno. $\mathrm{O}$ contraste $\mathrm{F}_{2}$ vs $\mathrm{F}_{2}$ recíproco não foi significativo, reforçando que os fenótipos destas sementes são semelhantes e que representaram a expressão do genótipo das gerações $F_{1}$ e $F_{1}$ recíproco, respectivamente (Figura 1). Por conseguinte, em grãos $\mathrm{F}_{2}$, o tegumento será $\mathrm{F}_{2}$ e os cotilédones serão $\mathrm{F}_{1}$ e a seleção não é recomendada, pois será totalmente ineficaz.

Resultado semelhante foi verificado na combinação "TPS Bonito" $\left(0,58 \mathrm{~g} \mathrm{~kg}^{-1}\right.$ de MS $)$ “ "BRS Expedito" $\left(0,94 \mathrm{~g} \mathrm{~kg}^{-1}\right.$ de MS), em que a utilização de genitores contrastantes para o teor de cálcio em grãos de feijão possibilitou a identificação de efeito materno, uma vez que o contraste $F_{1}$ vs $F_{1}$ recíproco foi significativo e não foram constatadas diferenças entre as gerações $\mathrm{F}_{2}$ e $\mathrm{F}_{2}$ recíproco (Figura 1). Em razão disso, a expressão genética do teor de cálcio do cruzamento somente será observada em $\mathrm{F}_{2}$ quando as sementes apresentarão cotilédones em geração $\mathrm{F}_{1}$ e tegumento em geração $F_{2}$. Conseqüentemente, a seleção deverá ser postergada para $\mathrm{F}_{3}$ (grãos com cotilédones em geração $F_{2}$ e tegumento em geração $F_{3}$ ), quando segregação máxima será constatada nessa geração.

A ocorrência de efeito materno já havia sido observada para o teor de proteína (LELEJI et al., 1972) e para o tempo de cozimento em grãos de feijão (RIBEIRO et al., 2006). Isso posto, há inequívoca relevância na investigação da ocorrência de efeito materno para os caracteres que conferem qualidade nutricional e tecnológica ao feijão, pois tegumento e cotilédones são tecidos que estão presentes em gerações diferentes (RAMALHO et al., 2000), o que terá implicações diretas na seleção e na condução de populações segregantes em programas de melhoramento.
Os teores de cálcio variaram de $0,58 \mathrm{~g}$ ("TPS Bonito") a $0,94 \mathrm{~g} \mathrm{~kg}^{-1}$ de MS ("BRS Expedito" e $\mathrm{F}_{1}$ do cruzamento "Pérola" x "TPS Bonito" (Tabela 2). Esses valores foram similares aos teores observados por BARAMPAMA \& SIMARD (1993) e inferiores aos verificados por GUZMAN-MALDONADO et al. (2000) e por MESQUITA et al. (2007).

Considerando que o teor de cálcio em feijão é função do tegumento dos grãos, a geração dos cotilédones foi considerada para a obtenção das estimativas de herdabilidade e de ganhos por seleção (Tabela 2). A decomposição da variância fenotípica evidenciou a predominância dos efeitos genéticos em relação aos de ambiente nas duas combinações híbridas (Tabela 2). Como a proporção entre a variância genética e a variância fenotípica expressa a herdabilidade, em sentido amplo, valores considerados altos para essa estimativa foram obtidos. Assim, herdabilidade, em sentido amplo, de $66,75 \%$ foi obtida no cruzamento entre "Pérola" x "TPS Bonito" e de 74,65\% na combinação "TPS Bonito" x "BRS Expedito". Valores de herdabilidade, em sentido amplo, de 48 a 50\% foram obtidos para o teor de cálcio em vagens e grãos imaturos de feijão (QUINTANA et al., 1999).

A variância aditiva foi responsável pela maior parte da variância genética em ambos os cruzamentos e as estimativas de herdabilidade, em sentido restrito, de moderada a alta foram obtidas: de $47,00 \%$ para a combinação "Pérola" x "TPS Bonito" e de $63,61 \%$ para a combinação "TPS Bonito" x "BRS Expedito" (Tabela 2). No melhoramento de autógamas, é consabido que a predominância de variância aditiva na expressão de um caráter é de grande importância, pois os ganhos seletivos dependerão apenas da variância gamética (CARVALHO et al., 2001; CRUZ, 2005). Por conseguinte, métodos intrapopulacionais são recomendados para a obtenção de ganhos superiores em gerações avançadas, oriundas dos cruzamentos 




realizados. Nesse aspecto, com fulcro nas magnitudes das herdabilidades no sentido restrito, são obtidos ganhos seletivos promissores com a adoção do método genealógico ou mesmo SSD para os segregantes da combinação "Pérola" x "TPS Bonito", ao passo que as estratégias bulk e o próprio SSD são os mais adequados para a capitalização de respostas seletivas entre os segregantes do par "TPS Bonito" x "BRS Expedito".

Com relação às estimativas de heterose percentual com base na média dos genitores, foram constatados valores positivos para ambas as combinações híbridas (Tabela 2); para a heterobeltiose, no cruzamento "Pérola" x "TPS Bonito", a expressão de valor positivo de $(9,45 \%)$ denota a ocorrência de efeito de sobredominância. Porém, esse comportamento não se repetiu no cruzamento "TPS Bonito" $\mathrm{x}$ "BRS Expedito", em que houve estimativa negativa $(-10,50 \%)$ para a heterobeltiose.

Valores máximos na geração $\mathrm{F}_{2}$, superiores aos valores obtidos nos genitores, foram detectados em ambos os cruzamentos, denotando a ocorrência de segregação transgressiva para o teor de cálcio em grãos de feijão. Valores de $1,29 \mathrm{~g} \mathrm{~kg}^{-1}$ de MS para o cruzamento "Pérola" x "TPS Bonito" e de 1,47g kg-1 de MS para o cruzamento "TPS Bonito" $\mathrm{x}$ "BRS Expedito" foram obtidos, representando um incremento de $27,72 \%$ e de 
Tabela 2 - Estimativas das médias dos genitores $\left(\mathrm{P}_{1}\right.$ e $\left.\mathrm{P}_{2}\right)$ e das gerações $\mathrm{F}_{1}, \mathrm{~F}_{2}$, retrocruzamento 1 ( $\left.\mathrm{RCP}_{1}\right)$ e retrocruzamento 2 (RCP $)$ com base na geração dos cotilédones e seus respectivos desvios-padrão, parâmetros genéticos e predição de ganhos por seleção para o teor de cálcio nos grãos de feijão dos cruzamentos "Pérola” x “TPS Bonito” e "TPS Bonito” x "BRS Expedito”. Santa Maria - RS, UFSM, 2007.

\begin{tabular}{|c|c|c|}
\hline \multirow{2}{*}{ Genitores e Gerações } & \multicolumn{2}{|c|}{ - } \\
\hline & "Pérola" $\left(\mathrm{P}_{1}\right) \mathrm{x}$ "TPS Bonito" $\left(\mathrm{P}_{2}\right)$ & "TPS Bonito" $\left(\mathrm{P}_{1}\right) \mathrm{x}$ "BRS Expedito" $\left(\mathrm{P}_{2}\right)$ \\
\hline$\overline{\bar{P}_{1}}$ & $0,86 \pm 0,15$ & $0,58 \pm 0,17$ \\
\hline$\overline{\mathrm{P}}_{2}$ & $0,58 \pm 0,17$ & $0,94 \pm 0,13$ \\
\hline$\overline{\mathrm{F}}_{1}$ & $0,94 \pm 0,24$ & $0,84 \pm 0,14$ \\
\hline$\overline{\mathrm{F}}_{2}$ & $0,75 \pm 0,33$ & $0,75 \pm 0,29$ \\
\hline$\overline{\mathrm{RCP}}_{1}$ & $0,76 \pm 0,36$ & $0,78 \pm 0,27$ \\
\hline$\overline{\mathrm{RCP}}_{2}$ & $0,70 \pm 0,19$ & $0,70 \pm 0,21$ \\
\hline Média & 0,77 & 0,76 \\
\hline CVE $(\%)$ & 36,38 & 30,65 \\
\hline Variância fenotípica $\left(\sigma_{\mathrm{P}}^{2}\right)$ & 0,107626 & 0,083726 \\
\hline Variância ambiente $\left(\sigma_{\mathrm{E}}^{2} \mathrm{~F}_{2}\right)$ & 0,035787 & 0,021224 \\
\hline Variância genética $\left(\sigma_{\mathrm{G}}^{2}\right)$ & 0,071839 & 0,062502 \\
\hline Variância aditiva $\left(\sigma_{\mathrm{A}}^{2}\right)$ & 0,050589 & 0,053261 \\
\hline Herdabilidade ampla $\left(\mathrm{h}_{\mathrm{a}}^{2}\right)$ & 66,75 & 74,65 \\
\hline Herdabilidade restrita $\left(\mathrm{h}_{\mathrm{r}}^{2}\right)$ & 47,00 & 63,61 \\
\hline Heterose $(\mathrm{H} \%)$ & 30,28 & 10,43 \\
\hline Heterobeltiose (HT \%) & 9,45 & $-10,50$ \\
\hline Valor máximo nos genitores & 1,01 & 1,10 \\
\hline Valor mínimo nos genitores & 0,43 & 0,43 \\
\hline Valor máximo na $\mathrm{F}_{2}$ & 1,29 & 1,47 \\
\hline Valor mínimo na $\mathrm{F}_{2}$ & 0,42 & 0,53 \\
\hline Plantas selecionadas na $\mathrm{F}_{2}$ & $19,21,20,16,4$ e 10 & $4,20,12,17,1$ e 9 \\
\hline Média original da $\mathrm{F}_{2}$ & 0,75 & 0,75 \\
\hline Média das plantas selecionadas & 1,21 & 1,14 \\
\hline Diferencial de seleção (DS) & 0,46 & 0,39 \\
\hline Ganho por seleção $(\Delta \mathrm{G})$ & 0,22 & 0,25 \\
\hline Ganho por seleção $(\Delta \mathrm{G} \%)$ & 28,47 & 32,99 \\
\hline Média predita para o primeiro ciclo após seleção & 0,97 & 1,00 \\
\hline
\end{tabular}

$33,64 \%$, respectivamente, no teor de cálcio nos grãos. Estes resultados comprovam que é possível aumentar o teor de cálcio nos grãos de feijão por meio de melhoramento intrapopulacional com segregantes de combinações contrastantes.

Considerando a pressão de seleção de $25 \%$, foi obtido o diferencial de seleção de $0,46 \mathrm{~g} \mathrm{~kg}^{-1}$ para o cruzamento "Pérola" $\mathrm{x}$ "TPS Bonito" e de $0,39 \mathrm{~g} \mathrm{~kg}^{-1}$ para "TPS Bonito" $\mathrm{x}$ "BRS Expedito", proporcionando ganhos significativos por meio da seleção truncada, de magnitudes de $0,22 \mathrm{~g} \mathrm{~kg}^{-1}(28,47 \%)$ e de $0,25 \mathrm{~g} \mathrm{~kg}^{-1}$ $(32,99 \%)$, respectivamente. Desse modo, ganhos consideráveis poderão ser observados já no primeiro ciclo de seleção intrapopulacional, possibilitando a obtenção de genótipos de feijão mais nutritivos para uso na alimentação.

\section{CONCLUSÕES}

Houve efeito materno na expressão do teor de cálcio em grãos de feijão. A seleção de plantas $F_{2}$ obtidas a partir de cruzamentos entre genitores contrastantes poderá ser efetiva na obtenção de genótipos de feijão com maior teor de cálcio nos grãos devido à expressão de estimativas moderada a alta de herdabilidade restrita e dos efeitos gênicos aditivos serem predominantes na expressão da característica.

\section{AGRADECIMENTOS}

Ao Conselho Nacional de Desenvolvimento Científico e Tecnológico (CNPq), pelo auxílio financeiro e pelas bolsas concedidas, e à Fundação de amparo à Pesquisa do Estado do Rio Grande do Sul (FAPERGS), pela bolsa de iniciação científica.

Ciência Rural, v.39, n.1, jan-fev, 2009. 


\section{REFERÊNCIAS}

BARAMPAMA, Z; SIMARD, R.E. Nutrient composition, protein quality and antinutritional factors of some varieties of dry beans (Phaseolus vulgaris) grown in Burundi. Food Chemistry, Easton, v.47, n.2, p.159-167, 1993.

CARVALHO, F.I.F. de. et al. Estimativas e implicações da herdabilidade como estratégia de seleção. Pelotas: UFPEL, 2001. 98p.

CRUZ, C.D. Princípios de genética quantitativa. Viçosa: UFV, 2005. 394p.

CRUZ, C.D. Programa Genes: biometria. Viçosa: UFV, 2006. $382 \mathrm{p}$

CZAJKA-NARINS, D.M. Minerais. In: KATHLEEN, M.L. Krause: alimentos, nutrição e dietoterapia. 9.ed. São Paulo: Roca, 1998. p.123-166.

FRANCO, G. Tabela de composição química dos alimentos. 9.ed. Rio de Janeiro: Atheneu, 1999. 307p.

GRUSAK, M.A. et al. Intrinsic $42 \mathrm{Ca}$-Labelling of green bean pods for use in human biovailability studies. Journal of the Science of Food and Agriculture, Chichester, v.70, n.1, p.11-15, 1996.

GUZMÁN-MALDONADO, S.H. et al. Protein and mineral content of a novel collection of wild and weedy common bean (Phaseolus vulgaris L). Journal of the Science of Food and Agriculture, Chichester, v.80, n.13, p.1874-1881, 2000.

LELEJI, O.I. et al. Inheritance of crude protein percentage and its correlation with seed yield in beans, Phaseolus vulgaris L. Crop Science, Madison, v.12, n.2, p.168-171, 1972.

MESQUITA, F.R. et al. Linhagens de feijão (Phaseolus vulgaris L.): composição química e digestibilidade protéica. Ciência e Agrotecnologia, Lavras, v.31, n.4, p.1114-1121, 2007.
MIYAZAWA, M. et al. Análises químicas de tecido vegetal. In: SILVA, F.C. Manual de análises químicas de solos, plantas e fertilizantes. Brasília: EMBRAPA Solos, 1999. p.171223 .

MORAGHAN, J.T. et al. Contrasting accumulations of calcium and magnesium in seed coats and embryos of common bean and soybean. Food Chemistry, Easton, v.95, n.4, p.554-561, 2006.

NATIONAL RESEARCH COUNCIL (NRC). Recommend dietary allowances. 10.ed. Washington DC: National Academy, 1989. 284p. (Food and Nutrition Board, Commission on Life Sciences.)

PETERNELLI, L.A.; BORÉM, A. Hibridação em feijão. In: BORÉM, A. Hibridação artificial de plantas. Viçosa: UFV, 1999. p.269-294

QUINTANA, J.M. et al. Comparison of pod calcium concentration between two snap bean populations. Journal of the American Society for Horticultural Science, Alexandria, v.124, n.3, p.273-276, 1999.

RAMALHO, M.A.P. et al. Genética na agropecuária. Lavras: UFLA, 2000. 472p.

RIBEIRO, S.R.R.P. et al. Maternal effect associated to cooking quality of common bean. Crop Breeding and Applied Biotecnology, Viçosa, v.6, n.4, p.304-310, 2006

SEBASTIÁ, V. et al. Effects of legume processing on calcium, iron and zinc contents and dialysabilities. Journal of the Science of Food and Agriculture, Sussex, v.81, n.12, p.11801185,2001

STEVENS, M.A. Varietal influence on nutritional value. In WHITE, P.L.; SELVEY, N. Nutritional quality of fresh and vegetables. New York: Futura Publishing, 1974. p.87110 .

WARNER, J.N. A method for estimating heritability. Agronomy Journal, Madison, v.44, n.8, p.427-430, 1952. 